\title{
Transcatheter coil embolotherapy: a safe and effective option for major colonic haemorrhage
}

\author{
A A Nicholson, D F Ettles, J E Hartley, I Curzon, P W R Lee, G S Duthie, J RT Monson
}

\begin{abstract}
Background-The management of major colonic bleeding is problematic. A proportion of patients require emergency surgery which is associated with high morbidity and mortality. Percutaneous embolotherapy, previously considered a high risk procedure in the colon, may provide an alternative treatment in this group of patients.
\end{abstract}

Aims-To assess the safety and efficacy of embolotherapy in the treatment of life threatening colonic haemorrhage.

Patients and methods-Thirty eight patients with fresh haemorrhage per rectum were referred for surgery because of failed conservative treatment. All underwent angiography; in 14 a bleeding site or vascular abnormality was detected. A coaxial catheter was directed to the most distal bleeding artery and this was embolised with platinum coils.

Results-Detection of a bleeding site correlated with haemodynamic stability at the time of angiography ( $r=1$ for a systolic blood pressure less than $100 \mathrm{~mm} \mathrm{Hg}$ ). Bleeding sites or vascular abnormalities were detected and embolised in 14 patients $(37 \%)$. In $12 / 14$ there was immediate and sustained haemodynamic improvement; two continued to bleed and required emergency hemicolectomy (14\%). Three developed ischaemic complications $(21.4 \%)$; these were managed conservatively and required no intervention. The 30 day mortality was $7.1 \%$ in the embolotherapy group and $10.5 \%$ in the overall group of 38 patients.

Conclusion-Colonic embolotherapy for life threatening haemorrhage is an effective, relatively safe procedure with a low incidence of major complications. Its use depends on the identification of a focal bleeding point or vascular abnormality, which in turn depends on the haemodynamic stability of the patient at the time of angiography.

(Gut 1998;43:79-84)

Keywords: colonic haemorrhage; embolisation; angiography; angiodysplasia; diverticular disease

Colonic haemorrhage which is severe enough to warrant surgical intervention is an uncommon event; it is however most frequently encountered in elderly patients who tolerate hypovolaemia poorly. Such patients pose major diagnostic and management problems. In particular the need to resuscitate the patient must be balanced against the need to identify the source of bleeding. The reported mortality following emergency colonic resection for bleeding ranges from 10 to $36 \% .{ }^{12}$ Some surgeons perform right hemicolectomy when the bleeding source is occult, ${ }^{3}$ and accept they will be wrong in a significant number of cases. Others perform a total colectomy with an attendant increase in mortality. The most common cause of bleeding in the colon was thought to be diverticular disease but postmortem studies have suggested that the source is likely to be from small angiodysplasias which are often associated. Angiography is the most accurate diagnostic test for determining the bleeding source. ${ }^{4}$ Logically it will be most effective when the patient is bleeding.

Various studies have reported positive findings in approximately $43 \%{ }^{4}$ to $87 \%{ }^{5}$ of patients with acute massive lower gastrointestinal haemorrhage when actively bleeding. In contrast, a source of bleeding is identified in only $20 \%$ of patients who are not actively bleeding. ${ }^{6}$ Emergency angiography is therefore best performed when the blood pressure is falling and the pulse rate rising despite volume replacement. As $95 \%$ of lower gastrointestinal bleeds settle with conservative measures true emergency angiography should be reserved for patients who are destined for laparotomy and colectomy because of profound haemodynamic instability. In practice a significant number of these patients will have temporarily stopped bleeding prior to angiography despite best efforts to free laboratory time and staff. However the development of sophisticated catheters and guide wires means that selective and superselective angiography is relatively easy and quick. This increases the yield of positive findings.

The development of transcatheter therapy for colonic haemorrhage was a logical extension of diagnostic angiography, given the desirability of avoiding emergency surgery. Transcatheter embolisation provides an attractive alternative because of the immediate haemostasis that can be achieved. As long ago as 1977, Goldberger and Bookstein advocated transcatheter embolisation ${ }^{7}$ but by 1982 they and others were reporting significant colonic infarction. ${ }^{8}$ The technique subsequently fell into disrepute. However, analysis of the early data suggests that the $7 \mathrm{~F}$ catheters and non-steerable wires used at that time only allowed embolisation of marginal arteries. Thus large areas of colon were rendered ischaemic. The development of hydrophilic steerable catheters and guide wires, as well as coaxial systems as small as $2 \mathrm{~F}$, allows the 


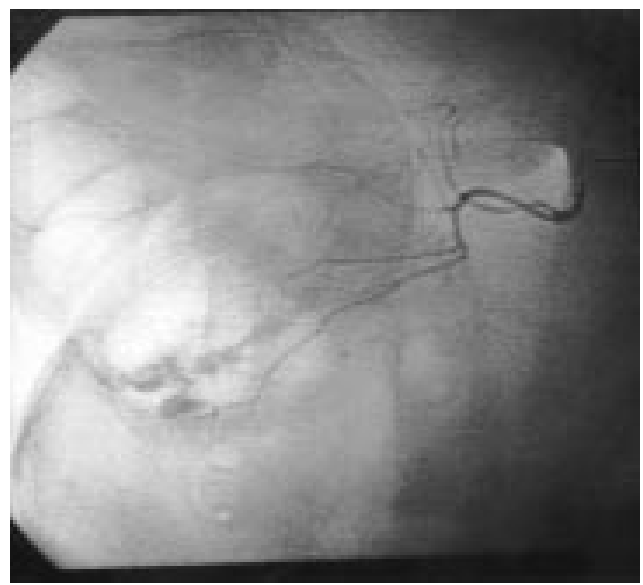

Figure 1 Digital subtraction angiography of the superior mesenteric artery, with superselective cannulation of a caecal branch of the ileocolic artery, showing haemorrhage into the caecal pole.



Figure 2 Introduction of a distal coil resulting in almost instantaneous arrest of haemorrhage.

delivery of small embolisation coils and alcohol coated particles to the bleeding point at the mucosal surface. Thus only small focal areas of colon are infarcted.

\section{Patients and methods}

Over a 24 month period from April 1995, 38 patients (18 men and 20 women; mean age 73 years, range 57-87) referred to Vascular Radiology for emergency mesenteric angiography for colorectal bleeding were considered for transcatheter embolotherapy. All patients were undergoing angiography in order to localise the source of haemorrhage prior to emergency colonic resection. Such patients were therefore actively bleeding at the time of referral, had failed to respond to conservative management, and were haemodynamically unstable despite continued transfusion. In practice only 17 were actively bleeding at the time of angiography, shown by blood pressure and pulse measurement before and during the procedure.

Initial inferior and superior mesenteric angiography was performed via a femoral approach using 5-French gauge femorovisceral catheters. Once the bleeding point was identified a 2.2-French gauge coaxial Tracker-18 catheter (Terumo, Piscataway, New Jersey, USA) was passed over a torquable seeker guide wire, down the femorovisceral catheter, to the bleeding site (fig 1). Superselective angiography was used to confirm the position of the catheter in relation to the bleeding point. Appropriate size platinum microcoils were then advanced down the catheter into the bleeding vessel using a pusher wire. Final superselective angiography confirmed coil position and cessation of bleeding (fig 2).

\section{Results}

Figure 3 shows the results of angiography. Of the 38 patients in the study, 17 were actively bleeding at the time of angiography as evidenced by hypotension, tachycardia (despite transfusion), and fresh blood per rectum. The appearance of contrast extravasation correlated perfectly with a systolic blood pressure of less than $100 \mathrm{~mm} \mathrm{Hg}(r=1)$. This appearance, indicating a colonic bleeding point, was identified and embolised in $13(76.5 \%)$. Of the other four, two were bleeding from the small bowel and two were bleeding from haemorrhoids; they are therefore considered no further. A vascular abnormality, a rectal angiodysplasia, ${ }^{9}$ was seen in only one of the 21 haemodynamically stable patients at the time of angiography $(4.8 \%)$, although 15 of the remaining 20 subsequently underwent elective colonic resection. Six microcoils were inserted to obliterate this as multiple proctoscopies and sigmoidoscopies had failed to establish the diagnosis.

The mean systolic blood pressure at the time of angiography was $76 \mathrm{~mm} \mathrm{Hg}$ (in two patients this was unrecordable), with a mean haemoglobin of $7.1 \mathrm{~g} / \mathrm{dl}$ (range $4-10 \mathrm{~g} / \mathrm{dl}$ ) despite a mean transfusion volume of 6 units (range 2-8 units). Table 1 presents the clinical details, angiography findings, and details and results of embolisation.

In 11 patients a single source of haemorrhage was identified. One patient was bleeding from two discrete sites in the right colon, and a further patient was bleeding diffusely from the left colon. Embolisation achieved haemostasis in 12 of the 14 patients, and in four of these only a single coil was required.

Two patients continued to bleed. One did so from a diffuse left sided Crohn's colitis. Multiple coils were placed in the marginal artery in the hope of achieving a degree of haemodynamic stability. The patient died from a postmortem examination confirmed cerebrovascular event 48 hours after emergency colonic resection. Angiography showed contrast extravasation at the hepatic flexure in a second patient. This was successfully embolised but the patient rebled at 24 hours. Repeat angiography failed to show the source of the recurrent bleed. Pathology revealed a hepatic flexure haemangioma following emergency right hemicolectomy.

A single patient had a persistent but haemodynamically insignificant bleed following embolisation. Sigmoidoscopy confirmed the angiographic diagnosis of a solitary rectal ulcer. This was successfully managed by insertion of an adrenaline soaked pack and formation of a covering stoma. The patient died of bronchopneumonia eight weeks later. 


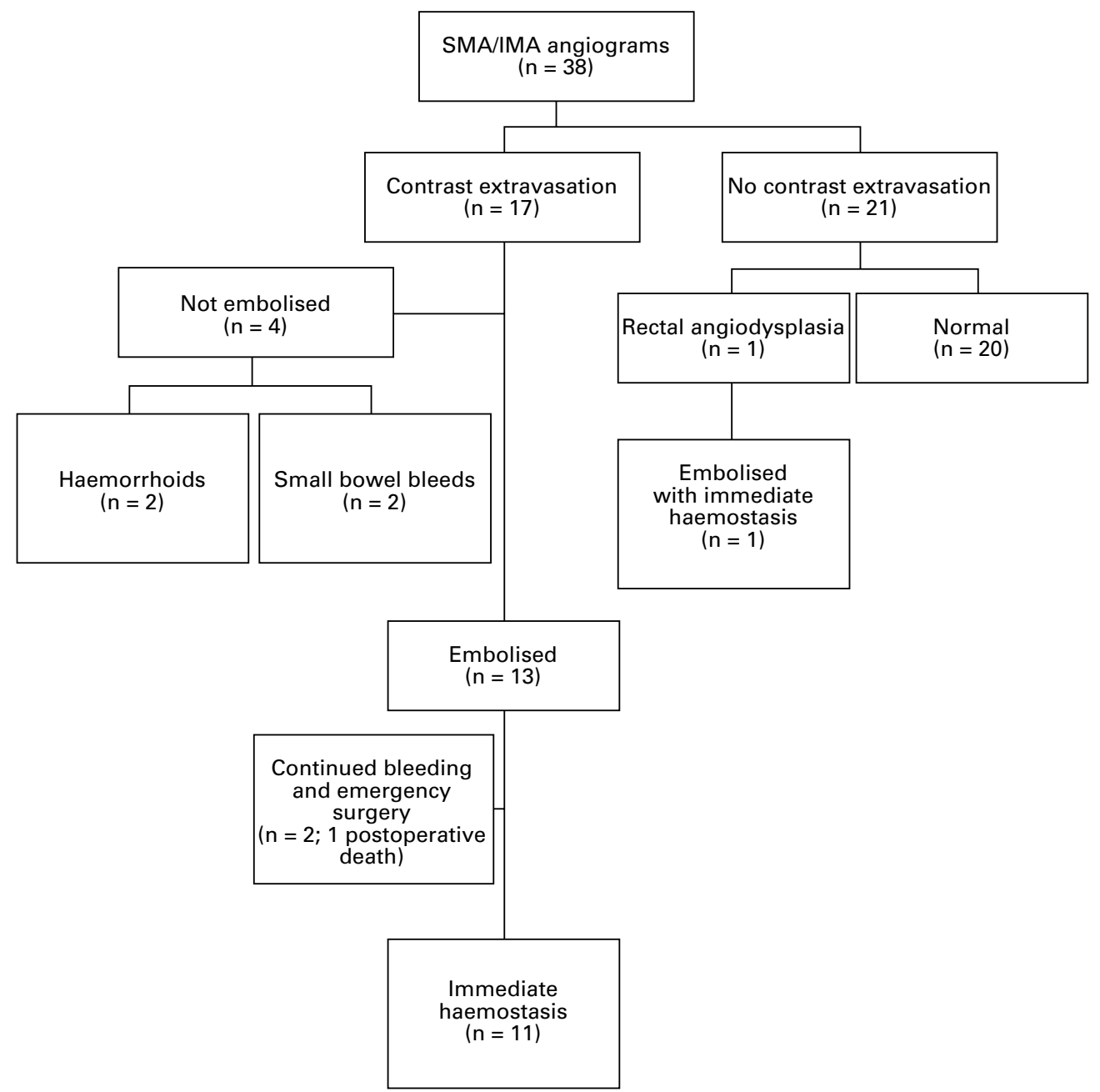

Figure 3 Results of angiography in patients with major colonic haemorrhage, April 1995 to April 1997. SMA, superior mesenteric artery; IMA, inferior mesenteric artery.

A second patient, having undergone successful embolotherapy for a middle colic arterial haemorrhage, later underwent elective right hemicolectomy for diverticular disease.

There were three ischaemic complications. In the first of these two areas of contrast extravasation were seen. Single coils were

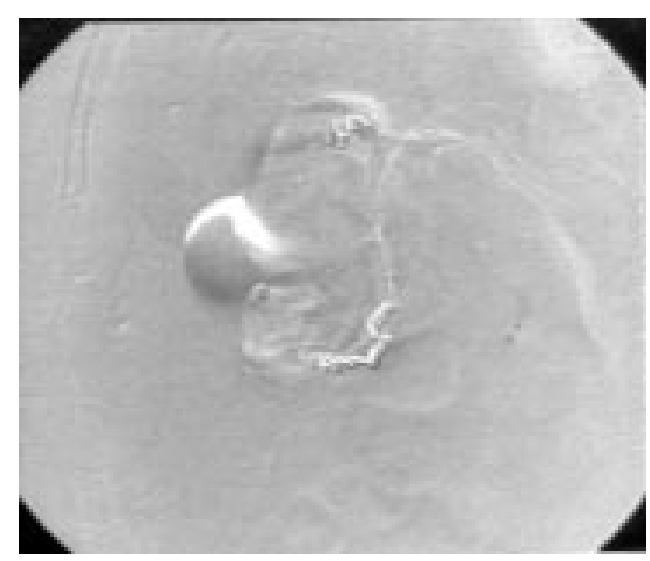

Figure 4 Angiography indicated bleeding sites at the hepatic flexure and caecal pole. The hepatic flexure coil was placed too close to the marginal artery. Though haemorrhage ceased immediately, an occult ischaemic stricture developed at the site (see fig 5). The caecal pole coils produced immediate haemostasis with no complications. inserted at the hepatic flexure and caecal pole to good haemostatic effect (fig 4). However the first coil, in the distal middle colic artery, was inadvertently placed more proximally than would be considered ideal. Routine double contrast barium enema investigation subsequently revealed a smooth stricture at the hepatic flexure (fig 5), the ischaemic nature of which was confirmed by colonoscopic biopsy. The patient remains asymptomatic 18 months later. The second ischaemic complication arose in a patient on dialysis with a life threatening splenic flexure haemorrhage. The marginal artery at this site was embolised because of difficulty in negotiating the "end artery". Clinical signs of ischaemic colitis developed six hours later. In the absence of peritonism or systemic upset, the patient was managed conservatively and settled over the ensuing 48 hours. Colonoscopy 72 hours post-angiography revealed a $10 \mathrm{~cm}$ segment of mucosal necrosis at the splenic flexure. The patient's further recovery was uneventful and she remains well 14 months later.

The patient with rectal angiodysplasia had a two year history of daily rectal bleeding prior to the life threatening bleed requiring emergency treatment. He had been fully investigated, apart from angiography, during several previ- 


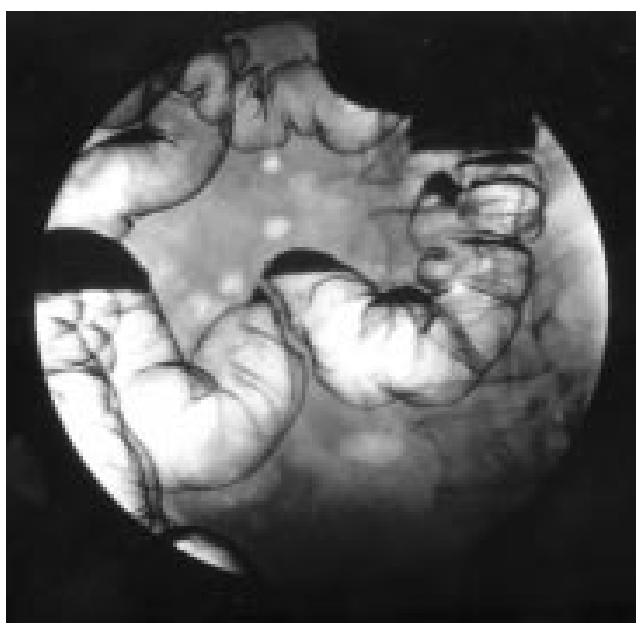

Figure 5 Ischaemic stricture at the hepatic flexure following coil embolisation in the middle colic artery territory (see fig 4).

ous admissions. Following embolisation there was immediate haemostasis. He had no further bleeding for four months but then developed intermittent minor blood loss and slight difficulty at defecation. Examination revealed a moderate rectal stenosis which would admit a rigid sigmoidoscope. At present this has been treated conservatively.

\section{Discussion}

Since transcatheter embolisation was first performed by Newton and Adams in $1967^{10}$ modifications of the technique have been used at numerous sites throughout the body, using a variety of embolic materials including gelfoam, autologous blood, and steel coils. ${ }^{11-13}$ Embolisation for colonic haemorrhage was first performed by Goldberger and Bookstein in $1977 .{ }^{7}$ However, despite early successes, ${ }^{14}{ }^{15}$ this approach has not been widely embraced because of reports of colonic ischaemia and infarction. ${ }^{816}$ Some degree of distal ischaemia is the inevitable consequence of embolisation. Technical developments over the past five years have allowed us to re-evaluate the potential of colonic embolotherapy. We believe that the particular value of the coaxial tracker catheter system lies in its ability to catheterise superselectively the "radiological end arteries" distally in the mesenteric arcade beyond the marginal artery. Platinum microcoils can then be placed extremely accurately in order to produce permanent occlusion of these vessels within minutes. ${ }^{17}$ These coils also have the advantage of avoiding the particulate reflux which is sometimes seen with other embolic materials. It is perhaps significant that early reports of post-embolisation ischaemia have

Table 1 Relevant clinical details and outcome of patients with major colonic haemorrhage treated by transcatheter coil embolotherapy

\begin{tabular}{|c|c|c|c|c|c|c|c|c|c|c|c|}
\hline $\begin{array}{l}\text { Patie } \\
n t\end{array}$ & $\begin{array}{l}\text { Age } \\
\text { (y) }\end{array}$ & Sex & History & $\begin{array}{l}\text { Pulse } \\
\text { (beats/ } \\
\text { min) }\end{array}$ & $\begin{array}{l}B P \\
(m g H g)\end{array}$ & $\begin{array}{l}\mathrm{Hb} \\
(\mathrm{g} / \mathrm{l})\end{array}$ & $\begin{array}{l}\text { Units } \\
\text { transfused }\end{array}$ & Angiography findings & Treatment & Result & Outcome \\
\hline 1 & 78 & $\mathrm{~F}$ & $\begin{array}{l}\text { Continuous } \\
\text { rectal bleed }\end{array}$ & 120 & 80 & 60 & 8 & $\begin{array}{l}\text { Superior haemorrhoidal } \\
\text { bleed from solitary } \\
\text { rectal ulcer }\end{array}$ & 2 coils & $\begin{array}{l}\text { Bleeding } \\
\text { stopped }\end{array}$ & $\begin{array}{l}\text { Temporary colostomy and } \\
\text { adrenaline swab for slight bleed at } \\
\text { sigmoidoscopy. Died } 8 \text { weeks } \\
\text { later of bronchopneumonia }\end{array}$ \\
\hline 2 & 72 & $M$ & $\begin{array}{l}5 \text { bleeds over } \\
72 \mathrm{~h}\end{array}$ & 120 & $95 / 60$ & 58 & 7 & $\begin{array}{l}\text { Bleed from caecal } \\
\text { branch and MCA }\end{array}$ & 2 coils & $\begin{array}{l}\text { Bleeding } \\
\text { stopped }\end{array}$ & $\begin{array}{l}\text { No further bleeding. Occult } \\
\text { ischaemic stricture at hepatic } \\
\text { flexure. Well at } 16 \text { months }\end{array}$ \\
\hline 3 & 83 & $\mathrm{~F}$ & $\begin{array}{l}4 \text { bleeds over } \\
48 \mathrm{~h}\end{array}$ & $>120$ & NR & 60 & 6 & $\begin{array}{l}2 \text { angiographies. First } \\
\text { no bleeding point } \\
\text { identified. Second bleed } \\
\text { from } \text { MCA }\end{array}$ & 3 coils & $\begin{array}{l}\text { Bleeding } \\
\text { stopped }\end{array}$ & $\begin{array}{l}\text { No further bleeding. Diverticular } \\
\text { disease on barium enema. Well at } \\
14 \text { months }\end{array}$ \\
\hline 4 & 71 & $M$ & $\begin{array}{l}\text { Continuous } \\
\text { bleed for } 12 \mathrm{~h}\end{array}$ & $>120$ & $90 / 70$ & 74 & 6 & Bleed from MCA & Single coil & $\begin{array}{l}\text { Bleeding } \\
\text { stopped }\end{array}$ & $\begin{array}{l}\text { No further bleeds. Elective right } \\
\text { hemicolectomy for diverticular } \\
\text { disease }\end{array}$ \\
\hline 5 & 84 & $\mathrm{~F}$ & $\begin{array}{l}6 \text { heavy bleeds, } \\
\text { previous right } \\
\text { hemicolectomy } \\
\text { for Crohn's } \\
\text { disease }\end{array}$ & $>120$ & 80 & 54 & 5 & $\begin{array}{l}\text { Diffuse bleed from left } \\
\text { colon }\end{array}$ & 10 coils & $\begin{array}{l}\text { Further } \\
\text { bleeding }\end{array}$ & $\begin{array}{l}\text { Emergency left hemicolectomy } \\
\text { for Crohn's colitis. CVA, died } 48 \\
\text { h later }\end{array}$ \\
\hline 6 & 86 & $\mathrm{~F}$ & $\begin{array}{l}4 \text { heavy bleeds } \\
\text { in } 12 \mathrm{~h}\end{array}$ & 100 & 80 & 73 & 6 & Bleed from RCA & Single coil & $\begin{array}{l}\text { Bleeding } \\
\text { stopped }\end{array}$ & $\begin{array}{l}\text { No further bleeds. Diverticular } \\
\text { disease on barium enema. Well at } \\
1 \text { year }\end{array}$ \\
\hline 7 & 87 & $\mathrm{~F}$ & $\begin{array}{l}4 \text { heavy bleeds } \\
\text { in } 12 \mathrm{~h}\end{array}$ & $>120$ & $95 / 60$ & 68 & 6 & $\begin{array}{l}\text { Bleed from caecal } \\
\text { artery }\end{array}$ & Single coil & $\begin{array}{l}\text { Bleeding } \\
\text { stopped }\end{array}$ & $\begin{array}{l}\text { No further bleeds. Diverticular } \\
\text { disease on barium enema. Well } 15 \\
\text { months later }\end{array}$ \\
\hline 8 & 86 & $\mathrm{~F}$ & $\begin{array}{l}\text { Protracted } \\
\text { bleeding over } \\
72 \mathrm{~h} . \text { Dialysis } \\
\text { patient }\end{array}$ & $>120$ & NR & 40 & 8 & Bleed from LCA & $\begin{array}{l}3 \text { coils in } \\
\text { marginal } \\
\text { artery }\end{array}$ & $\begin{array}{l}\text { Bleeding } \\
\text { stopped }\end{array}$ & $\begin{array}{l}\text { No further bleeds. Diverticular } \\
\text { disease. Segment of ischaemic } \\
\text { colon managed conservatively. } \\
\text { Well at } 14 \text { months }\end{array}$ \\
\hline 9 & 86 & $M$ & 3 heavy bleeds & $>120$ & 80 & 80 & 6 & Caecal branch & 3 coils & $\begin{array}{l}\text { Bleeding } \\
\text { stopped }\end{array}$ & $\begin{array}{l}\text { No further bleeding. Well at } 16 \\
\text { months }\end{array}$ \\
\hline 10 & 57 & $M$ & $\begin{array}{l}\text { Continuous } \\
\text { bleeding over } \\
24 \mathrm{~h} . \mathrm{PMH} \\
\text { regular rectal } \\
\text { bleeding }\end{array}$ & $>120$ & 100 & 93 & 4 & $\begin{array}{l}\text { Superior haemorrhoidal } \\
\text { angiodysplasia }\end{array}$ & 6 coils & $\begin{array}{l}\text { Bleeding } \\
\text { stopped }\end{array}$ & $\begin{array}{l}\text { No further bleeding. Well at } 3 \\
\text { months. Further minor bleeds at } \\
6 \text { months. Minor symptomatic } \\
\text { rectal stenosis }\end{array}$ \\
\hline 11 & 83 & $\mathrm{~F}$ & $\begin{array}{l}5 \text { heavy bleeds } \\
\text { in } 48 \mathrm{~h}\end{array}$ & $>120$ & 80 & 62 & 7 & $\begin{array}{l}\text { Superior haemorrhoidal } \\
\text { traumatic ulcer }\end{array}$ & Single coil & $\begin{array}{l}\text { Bleeding } \\
\text { stopped }\end{array}$ & $\begin{array}{l}\text { No further bleeding. Died } 33 \\
\text { days later of bronchopneumonia }\end{array}$ \\
\hline 12 & 79 & $\mathrm{~F}$ & $\begin{array}{l}\text { Continuous } \\
\text { bleeding over } \\
24 \mathrm{~h}\end{array}$ & 120 & 100 & 93 & 6 & Middle colic bleed & 4 coils & $\begin{array}{l}\text { Further } \\
\text { bleeding at } \\
24 \text { hours }\end{array}$ & $\begin{array}{l}\text { Right hemicolectomy. Hepatic } \\
\text { flexure haemangioma }\end{array}$ \\
\hline 13 & 86 & $M$ & 3 heavy bleeds & 110 & 100 & 100 & 4 & Caecal bleed & 2 coils & $\begin{array}{l}\text { Bleeding } \\
\text { stopped }\end{array}$ & $\begin{array}{l}\text { No further bleeding. Well at } 3 \\
\text { months }\end{array}$ \\
\hline 14 & 82 & $\mathrm{~F}$ & 5 heavy bleeds & 120 & 80 & 80 & 6 & $\begin{array}{l}\text { Rectal Dieulafoy's } \\
\text { disease }\end{array}$ & 2 coils & $\begin{array}{l}\text { Bleeding } \\
\text { stopped }\end{array}$ & $\begin{array}{l}\text { No further bleeding. Well at } 3 \\
\text { months }\end{array}$ \\
\hline
\end{tabular}

CVA, cardiovascular accident; NR, not recordable; MCA, middle colic artery; RCA, right colic artery; LCA, left colic artery; PMH, post medical history. 
followed procedures in which the secondary branches of the superior mesenteric artery were not selectively catheterised. ${ }^{8}$ In our experience significant ischaemia was only encountered when vessels proximal to the "end artery" were embolised-by either accident or design. We were perhaps fortunate in being able to manage both such patients conservatively. With the benefit of hindsight, if the "radiological end artery" cannot be catheterised, vasopressin infusion may be preferable to embolisation.

In the series presented here coil embolotherapy proved strikingly effective in the control of haemorrhage. This preliminary experience was deliberately limited to a highly selected group of patients who were haemodynamically unstable despite adequate attempts at resuscitation, and were destined for emergency laparotomy should embolisation fail to achieve haemostasis. We would therefore suggest that embolisation in fact saved 12 of the 14 patients from emergency colonic resection.

The patient in the embolotherapy group who died did so from a cerebrovascular accident following surgery. This was the only 30 day mortality in this group. There were four deaths in the 30 day period following angiography in the overall group of 38 patients. This difference was not statistically significant but there is a clear trend. The remaining patients are well after 3-20 months of follow up. A final diagnosis of diverticular disease was made in the majority of patients though this should be viewed with caution in the light of current thinking and also because the majority were bleeding from the right colon. Accurate diagnosis of the aetiology of colonic bleeding in the acute situation, particularly with relatively low resolution digital subtraction angiography, may be difficult. Published experience would suggest that most bleeding from the right colon is the result of angiodysplasia even in the presence of diverticulosis. ${ }^{18} 19$

Although the number of patients is small, their outcome compares favourably with reported success rates for vasopressin infusion which range from 31 to $91 \%$ for cessation of lower gastrointestinal haemorrhage. ${ }^{20-23}$ However embolisation, if ischaemic problems are avoided, has potential advantages over vasopressin infusion by virtue of the almost instant control of haemorrhage. In addition, major and minor morbidity rates of up to $40 \%$ have been reported following intra-arterial vasopressin infusion for colonic bleeding, ${ }^{24}$ with local and systemic ischaemia, ${ }^{25}$ reductions in cardiac output, hypertension, and cardiac arrhythmias all being documented. ${ }^{22}$

Clearly the decision whether to embolise or not depends on a number of factors. It should not be used in the patient who has not had a trial of conservative treatment. Angiodysplasias and other vascular abnormalities are rare. It is therefore important to see contrast extravasation. This will only happen if active bleeding is present at the time of angiography. The need to resuscitate the patient has to be weighed against the need to find the bleeding site and embolise it. If a vascular abnormality is seen the decision to embolise depends on its size and the number of arterial tributaries. It should be noted that embolisation of large angiodysplasias is likely to produce temporary cessation of bleeding at best as these lesions invariably have contributions from arteries that are too small to be seen at angiography but grow following occlusion of larger vessels. However embolisation may convert an emergency case into an elective one on a patient haemodynamically better able to withstand surgery. When rectal bleeding is seen careful consideration of other options has to be made. Endoscopic therapy may be effective. However if the bleeding is continuous and obscures the view of the operator or if numerous sigmoidoscopies have failed to show the abnormality then embolisation should be used.

The results of this series confirm the technical feasibility of transcatheter embolotherapy with platinum microcoils for the emergency control of significant colonic haemorrhage. With meticulous attention to technique, paying particular credence to the importance of superselective embolisation of "radiological end arteries", colonic ischaemia and infarction seem to be avoidable complications. Given appropriate levels of vascular radiological expertise and facilities, coil embolisation of active colonic bleeding can, in selected patients, obviate the requirement for emergency colonic resection. In view of the potential for procedure related complications these techniques should, at present, be reserved for use in actively bleeding patients who will require surgery should embolisation be unsuccessful.

1 Corman ML. Vascular diseases. In Corman ML, ed. Colon and rectal surgery. Philadelphia: JB Lippincott, 1993:860and rect 900 .

2 Leitman IM, Paull AE, Shires GT. Evaluation and management of massive lower gastrointestinal haemorrhage. Ann Surg 1989;209:175-80.

3 Spiller RC, Parkins RA. Recurrent GI bleeding of obscure origin. Report of 17 cases and a guide to logical management. Br F Surg 1983;70:489-93.

4 Fiorito JJ, Brandt LJ, Kozicky O, et al. The diagnostic yield of SMA angiography. Correlation with the pattern of GI bleeding. Am f Gastroenterol 1989;84:878-81.

5 Allison DJ, Hemmingway AP, Cunningham DA. Angiography in GI bleeding. Lancet 1982;ii:30-3.

phy in GI bleeding. Lancet 1982 ;ii:30-3.
6 Whittaker SC, Gregson RHS. The role of angiography in the investigation of acute or chronic GI haemorrhage. Clin Radiol 1993;47:382-8.

7 Goldberger LE, Bookstein JJ. Transcatheter embolisation for treatment of diverticular haemorrhage. Radiology 1977; 122:613-17

8 Rosenkrantz H, Bookstein JJ, Rosen RJ, et al. Postembolic colonic infarction. Radiology 1982;142:47-51.

9 Richards WO, Grove Mahoney P, Williams LF. Haemorrhage from a Dieulafoy-like lesion in the colon-a new cause of lower gastrointestinal bleeding. Am Surg 1988;54: $121-4$.

10 Newton TH, Adams JE. Angiographic demonstration and non-surgical embolisation of spinal cord angioma. Radiology 1968;91:873-6.

11 Matolo NM, Link DP. Selective embolisation for control of gastrointestinal haemorrhage. Am F Surg 1979;138:840-4.

12 O'Halpin D, Legge D, Macerlean DP. Therapeutic arterial embolisation: report of five years experience. Clin Radiol 1984;35:85-93.

13 Chalmers AG, Robinson PJ, Chapman AH. Embolisation in small bowel haemorrhage. Clin Radiol 1986;37:379-81.

14 Lawler G, Bircher M, Spencer J, et al. Embolisation in colonic bleeding. Br f Radiol 1985;58:83-4.

15 Sniderman KW, Franklin J, Sos TA. Successful transcatheter gelfoam embolisation of a bleeding cecal vascular ectasia. Am ₹ Roentgenol 1978;131:157-9.

16 Mitty HA, Efremedis S, Keller RJ. Colonic stricture after transcatheter embolisation for diverticular bleeding. AfR Am f Roentgenol 1979;133:519-21.

17 Kaufman SL, Martin LG, Zuckerman AM, et al. Peripheral transcatheter embolisation with platinum microcoils. Radiology 1992;184:369-72. 
18 Baum S, Athanasoulis CA, Waltman AC. Angiographic diagnosis and control of large bowel bleeding. Dis Colon diagnosis and control

19 Spencer J. Lower gastrointestinal bleeding. Br f Surg 1989; 76:3.

20 Browder W, Cerise EJ, Litwin MS. Impact of emergency angiography in massive lower gastrointestinal bleeding. Ann Surg 1986;204:530-6.

21 Gomes AS, Lois JF, McCoy RD. Angiographic treatment of gastrointestinal hemorrhage: comparison of vasopressin infusion and embolisation. AfR Am F Roentgenol 1986;146 $1031-7$.
22 Clark RA, Colley DP, Eggers FM. Acute arterial gastrointestinal hemorrhage: efficacy of transcatheter control. $A f R$

23 Rahn NH, Tishler JM, Han SY, et al. Diagnostic and interventional angiography in acute gastrointestinal haemorrhage. Radiology 1982;143:361-6.

24 Sherman LM, Shenoy SS, Cerra FB. Selective intra-arterial vasopressin. Clinical efficacy and complications. Ann Surg 1979;189:298-302.

25 Last MA, Lavery IC. Major haemorrhage and perforation due to a solitary caecal ulcer in a patient with end-stage renal failure. Dis Colon Rectum 1983;26:495-8. 